\title{
EDITORIALS
}

\section{In This Issue: Mindfulness in Practice and Policy}

\author{
Kurt C. Stange, $M D, P b D$, Editor
}

Ann Fam Med 2013;398-399. doi:10.1370/afm.1568.

$\mathrm{P}$ ressures to do more clinical care and administrative work in less time can result in clinicians who are speeded up, scattered in attention, and focused on minutia rather than what matters-in a word-mindless. Mindless practice is not what patients, clinicians, or health care designers want, despite each potentially making decisions that unintentionally foster churning, ill-focused practice. Thus it is heartening that articles in this issue both highlight the need for mindfulness and demonstrate its effectiveness.

Beach and colleagues measure mindfulness in 45 clinicians and then assess the quality of their interactions with patients infected with the human immunodeficiency virus. They find that mindful clinicians are more likely to be patient centered in their communications, more positive in their emotional tone with patients, and more likely to be rated highly on communication and overall satisfaction by patients. ${ }^{1}$ The authors call for research on interventions to improve mindfulness.

Fortney and colleagues perform such an intervention, engaging 30 primary care clinicians in a short mindfulness course. ${ }^{2}$ They focus on clinician, rather than patient, outcomes and find reductions in burnout (emotional exhaustion, depersonalization, and personal accomplishment), depression, anxiety, and stress, but no effect on resilience or compassion.

These studies of individuals show the need to pay attention to whether the environment in which clinicians practice and patients receive care promotes mindful- or mindlessness. Kannai provides a poignant reflection on her practice environment in exploring the multifarious effects of her health maintenance organization's new requirement to punch a time clock. ${ }^{3}$

The policy environment is scrutinized in several articles in this issue. Chang and Davis analyze the potential characteristics and effects of new Medicare enrollees under the Patient Protection and Affordable Care Act. ${ }^{4}$ DeVoe reflects on the potential of the medical home in helping people to reap the benefits in health outcomes shown to accrue to those with health insurance. ${ }^{5}$ Two editorials provide further insights. Silvers reviews the objectives of the Affordable Care Act and analyzes likely outcomes in light of the imperfect hand of the market in health care. ${ }^{6}$ Derksen highlights 3 urgent tasks that must be accomplished for the Affordable Care Act to be effective. ${ }^{7}$

Goad et al show the potentially important public health effect pharmacies can make by providing vaccines during convenient times that expand access to particular groups of people. ${ }^{8}$

Llanwarne and colleagues find little correlation between quality of care assessed by clinical measures and that assessed by patient experience measures, concluding that both are needed to avoid getting an unbalanced picture of quality. ${ }^{9}$

Several articles in this issue provide interesting and useful new clinical information.

Bruggink and colleagues show us the surprisingly high prevalence and the natural history of warts in schoolchildren. ${ }^{10}$

In an article featured in this issue's Annals Journal Club, Knotterus and colleagues provide a sophisticated analysis of different approaches to diagnosing urinary tract infections in women, finding that 3 questions, sometimes followed by a urine dipstick test, can provide a practical level of accuracy. ${ }^{11}$

A meta-analysis helps to clarify the effect of cinnamon on glucose and lipid profiles in people with diabetes. ${ }^{12}$ Presumably the heterogeneous but generally positive results do not support frequent indulgence in cinnamon pastries or taking the "cinnamon challenge" http://www.cinnamonchallenge.com/.

A novel Web-based tool for detecting unhealthy behaviors and mental health issues, eCHAT (electronic Case-finding and Help Assessment Tool) is found by Goodyear-Smith and colleagues to be feasible, acceptable, and easily integrated into the electronic medical record in $2 \mathrm{New}$ Zealand general practices. ${ }^{13}$

Finally, we are delighted to welcome 2 new members to the Annals team. Lars E. Peterson, MD, PhD, is our newest associate editor. Lars recently completed a family medicine residency at the Medical University of South Carolina, having obtained his doctor of medicine and doctorate at Case Western Reserve University. He holds the posts of Research Director, 
American Board of Family Medicine, and Assistant Professor, University of Kentucky Department of Family and Community Medicine.

Kathleen Rowland, MD, MS, is the Annals' first editorial intern. Kate is Clinical Assistant Professor, Department of Family Medicine at the University of Chicago, and Editor in Chief, Priority Updates from the Research Literature, Journal of Family Practice Family Physicians Inquiries Network. She will work on several projects that further develop the capacity of Annals to serve our diverse communities and provide her with editorial experience. We look forward to the energy and creativity that Lars and Kate bring.

We welcome your reflections at http://www.AnnFamMed.org.

\section{References}

1. Beach MC, Roter D, Korthuis PT, et al. A multicenter study of physician mindfulness and health care quality. Ann Fam Med. 2013;11(5): 421-428.

2. Fortney L, Luchterhand C, Zakletskaia L, Zgierska A, Rakel D. Abbreviated mindfulness intervention for job satisfaction, quality of life, and compassion in primary care clinicians: a pilot study. Ann Fam Med. 2013;11(5):412-420.

3. Kannai R. Measuring up: musings of a family doctor on the employee time clock. Ann Fam Med. 2013;11(5):477-480.

4. Chang T, Davis M. Potential adult Medicaid beneficiaries under the Patient Protection and Affordable Care Act compared with current adult Medicaid beneficiaries. Ann Fam Med. 2013;11(5):406-411.
5. DeVoe JE. Being uninsured is bad for your health: can medical homes play a role in treating the uninsurance ailment? Ann Fam Med. 2013;11(5):473-476.

6. Silvers JB. The Affordable Care Act: objectives and likely results in an imperfect world. Ann Fam Med. 2013;11(5):402-405.

7. Derkson DJ. The Affordable Care Act: unprecedented opportunities for family physicians and public health. Ann Fam Med. 2013; 11(5):400-402.

8. Goad JA, Taitel MS, Fensterheim LE, Cannon AE. Vaccinations administered during off-clinic hours at a national community pharmacy: implications for increasing patient access and convenience. Ann Fam Med. 2013;11(5):429-436.

9. Llanwarne NR, Abel GA, Elliott MN, et al. Relationship between clinical quality and patient experience: analysis of data from the English Quality and Outcomes Framework and the national GP Patient Survey. Ann Fam Med. 2013;11(5):467-472.

10. Bruggink SC, Eekhof JAH, Egberts PF, van Blijswijk SCE, Assendelft WJJ, Gussekloo J. Natural course of cutaneous warts among primary schoolchildren: a prospective cohort study. Ann Fam Med. 2013;11(5):437-441.

11. Knottnerus BJ, Geerlings SE, Moll van Charante EP, ter Riet G. Toward a simple diagnostic index for acute uncomplicated urinary tract infections. Ann Fam Med. 2013;11(5):442-451.

12. Allen RW, Schwartzman E, Baker WL, Coleman Cl, Phung OJ. Cinnamon use in type 2 diabetes: an updated systematic review and meta-analysis. Ann Fam Med. 2013;11(5):452-459.

13. Goodyear-Smith F, Warren J, Bojic M, Chong A. eCHAT: lifestyle and mental health screening in primary care. Ann Fam Med. 2013;11(5):460-466. 